\title{
Model Pertukaran Pada Masyarakat Nusantara Kuna Kajian (Pengujian) Arkeologis
}

\section{Bugie Kusumohartono}

Keywords: modelling, barter, economy, trade, archaeology

\section{How to Cite:}

Kusumohartono, B. Model Pertukaran Pada Masyarakat Nusantara Kuna Kajian (Pengujian) Arkeologis. Berkala Arkeologi, 15(3), 105-110. https://doi.org/10.30883/jba.v15i3.680

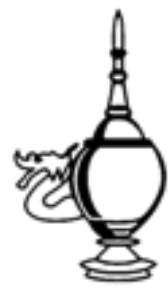

Berkala Arkeologi

https://berkalaarkeologi.kemdikbud.go.id/

Volume 15 No. 3, 1995, 105-110

DOI: $10.30883 /$ jba.v15i3.680

This work is licensed under a Creative Commons Attribution-NonCommercialShareAlike 4.0 International License. 


\title{
MODEL PERTUKARAN PADA MASYARAKAT NUSANTARA KUNA : KAJIAN (PENGUJIAN) ARKEOLOGIS
}

\author{
Bugie Kusumohartono \\ (Balai Arkeologi Yogyakarta)
}

\section{Pertukaran Dalam Arkeologi}

Salah satu bentuk perilaku ekonomi yang paling awal dalam kebudayaan manusia adalah pertukaran (exchange). Dari segi proses, pertukaran adalah penyebaran benda secara keruangan, dari individu ke individu lain, dan dari satu kelompok ke kelompok lain (Earle, 1982). Karena itu kajian pertukaran memberi tekanan pada kesalingterkaitan antara transaksi barang dengan organisasi masyarakat (Earle dan Ericson, 1977).

Studi pertukaran mencoba untuk selalu dapat memahami proses yang berlangsung dalam pemindahan barang dari satu tangan ke tangan yang lain dan dari satu kelompok manusia ke kelompok manusia yang lain. Dalam kaitan ini - merujuk Schiffer (1976) - arkeologi berupaya untuk menjembatani kesenjangan dalam memahami proses yang muncul di antara perilaku manusia dan budaya bendawi.

Manusia - baik secara individual maupun secara sosial -- merupakan aspek kuat dalam pertukaran. Dua aspek penting ini mendasari munculnya dua kubu pendekatan dan teori yang saling berbeda dalam memahami fenomena pertukaran tersebut. Yang memberi tekanan utama pada aspek individual berkelompok dalam kubu formalism, sedangkan vang memberi tekanan besar pada aspek kemasyarakatan tergabu'ng dalam kubu substantivism.

Karena beranjak dari aspek individu, pendekatan yang pertama memperlihatkan perhatian yang lebih khusus pada pertukaran dalam kerangka proses pengambilan keputusan bagi kepentingan populasi dan evolusi yang ditimbulkan oleh proses tersebut sebagai akibat dari upaya penekanan biaya ekonomik dan efisiensi. De-ngan demikian pendekatan ini akan dapat memo-tret organisasi dari sistem pertukaran tersebut, khususnya pada aspek regulasi kelembagaan yang berhubungan dengan distri-busi dan nilai atas barang (Earle 1982; Hodder 1982).

Sementera itu kubu yang kedua beranggapan bahwa aktivitas perekonomian berada di dalam suatu kelembagaan umum sosialpolitik. Oleh karena itu kegiatan perekonomian -- dalam hal ini pertukaran - secara khusus mencerminkan sistem sosialpolitik, dan pola kebudayaan. Pada sisi ini, pendekatan substantivism mengembangkan minatnya pada aspek-aspek lain dari kebudayaan, sehingga pertukaran memperlihatkan kaitan yang erat dengan aspek simbolik. sofistikasi sosial, dan aspek proses perubahan kebudayaan (Earle 1982; Hodder 1982).

\section{Model Pertukaran Redistribusi Nusantara Kuna}

Dengan merujuk pada K. Polanyi, Hodder (1978) mengklasifikasikan mekanisme pertukar-an "primitif" atas tiga kategori, yaitu:

1. Pertukaran resiprokal (reciprocal);

2. Pertukaran redistribusi (redistributive) dan

3. Pertukaran pasar tradisional (tradisitional market).

Pertukaran resiprokal adalah kewajiban memberi dan menerima di antara di antara individu yang berbeda hubungan sosialnya. Sementara itu yang disebut dengan pertukaran redistribusi berkaitan dengan kewajiban membayarkan barang dan jasa kepada pemuka masyarakat (misal: raja, kepala, pendeta), yang kemudian membagikan sebagian perolehannya baik untuk kepentingan umum maupun sebagai hadiah bagi seseorang. $D$ luar model pertukaran resiprokal dan redis-tribusi, masyarakat tradisional kemungkinan me-nerapkan model pertukaran pasar tradisional. Da-lam sistem ini, para pelakunya tidak memiliki ika-tan sosial tertentu yang mewajibkan mereka un-tuk melakukan pertukaran dan dimungkinkan adanya tawàr-menawar di dalamnya.

Di kawasan Asia Tenggara dan Pasifik ditengarai berkembangnya suatu sistem pertukaran yang bersifat redistribusi Pertukaran tersebut melibatkan elite masyarakat di satu pihak, dan warga masyarakat kebanyakan di pihak yang lain Dalam berbagai rujukan, elite masyarakat yang dimaksud sering disebut dengan istilah big men. Big men memiliki otoritas untuk mengatur atau mengarahkan kegiatan kaumnya (subordinat) (Malinowski, 1922). Otoritas tersebut tercermin. misainya pada pengendalian distribusi lahan, menetapkan upeti yang diterima dari warga masyarakat (Bellwood, 1987), maupun dalam bentuk yang lebih terbatas, misalnya sebatas persuasi dan pengaruhnya pada proses pengambilan keputusan dalam klen.(Rappaport, 1984). Namun hal itu menjadi signifikan manakala kasus-kasus yang diputuskan berkaitan dengan permasalahan perang, upacara, wanita, dan lahan pertanian.

Status khusus tersebut diperoleh meialui prestasi tertentu (achieved), dan bukan turun-te- 
murun (heredity) (Jennings, 1979). Selain itu status khusus tersebut berkaitan erat dengan kewajiban untuk memberi, hal ini merupakan esensi dari potlatch (Mauss, 1992), misainya da:am bentuk penyelenggaraan pesta jasa (feast of merit, feast-giving) oleh "calon" big man dan bahkan persaingan antar big man tercermin pada penyelenggaraan pesta-pesta jasa tersebut (Oliver. 955). Dengan kata lain kemurah-hatian (generosity) memiliki motivasi kuat pada tujuan politik

Seorang kepala suku akan dapat tetap mempertahankan kekuasaan atas suku. desa dan keluarganya, dan telap menduduki posisinya seba-gai kepala dalam lingkungan bangsanya maupun di luar, hanya bila ia dapat membuktikan bahwa ia disayangi oleh para roh dan memiliki keberuntungan dan bahwa ia terpengaruh oleh keberuntungan Cara satu-satunya untuk mempertunjukkan keberuntungannya tersebut ialah dengan memboroskannyz bagi penghinaan orang-orang lainnya jengan mendudukan mereka itu sebagai "dalam. naungan namanya"... (Mauss, 1992: 56)

Pembesar-pembesar pada masyarakat tradisional umumnya, termasuk suku-suku dari Polynesia sampai Afrika, biasanya hanya mencapai pangkat tinggi karena mampu menyalurkan manfaat berupa bahan kepada sejumiah anak buah yang :ebih besar dari orang lain (Miksic, 1981).

Dengan kata lain, dalam konsep ini kemu-rahhatian merupakan atribut pokok bagi kekuasa-an. Di balik itu tentu pada dasarnya para big men haruslah individu yang memiliki status ekonomi tinggi dalam komunitasnya, sehingga dapat meme-nuhi "kewajiban" bagi subordinatnya (Bellwood, 1987 Malinowski, 1922: Oliver, 1955)

Diduga kuat pesta-pesta jasa telah dipraktekkan sekurangnya pada fase budaya Megalitik di Nusantara. Menurut para pakar prasejarah Nusantara, penyelenggaraan pesta jasa ditandai dengan pendirian suatu menhir (Soejono, 1984), yang diduga kuat merupakan monumen yang menandai diperolehnya status big man oleh si penyelenggara pesta jasa. Penghormatan kepada sang big man berlanjut terus walaupun yang bersangkutan telah mati, dan bahkan Soejono (1984) menginterpretasikan bahwa menhir-monumen penanda pesta jasa akhirnya menjadi personifikasi dari tokoh yang bersangkutan. Menhir tersebut berfungsi sebagai media komunikasi antara dunia hidup dengan alam arwah, sehingga walaupun telah mati namun kemurahhatian sang tokoh dapat tetap diminta dan dinikmati oleh subordinatnya.

Di Jawa saat ini, penyelenggaraan pesta ja-sa terlihat mencolok manakala berlangsung pelaksanaan proses kegiatan pemilihan Jurah di desadesa. Para calon lurah berkompetisi dalam hal penyaluran barang dan bahan kepada komunitasnya untuk menjaring dukungan suara sebanyak mungkin. Simpati dari para pendukung tidak diperolen melalui rancangan program yang yang berprospek baik, namun diperoleh dari intensitas kemurahhatian calon lurah yang bersangkutan

\section{Pertukaran Nusantara Kuna}

Dengan merujuk pada paparan di atas model pertukaran redistribusi bukan mustahil berkeribang pula di Nusantara pada jaman kuna (sekıtar abad $V$-XVI M). Suatu pengujian pada sumbersumber tekstual telah dilakukan, dan memperoleh gambaran tentang pertukaran redistribusı yang pernah berkembang pada masyarakat Jawa Kuna (Kusumohartono, 1991).

Data-data yang relevan --dalam hal ini berhubungan dengan segi-segi sosial dan ekonomi .. dari periode klasik awal disajikan oleh J.N. Miksic (1981). Berdasarkan catatan-catatan perjalanan pelaut Eropa, Geografi dan Periplus Mare Erythaerus, sekurangnya sejak abad ke-2 Masehi teian berlangsung kegiatan perniagaan dengan masyarakat Nusantara. Kekhususan dari sistem perniagaan tersebut adalah prosedurnya yang tidak di. sandarkan pada hukum pasar namun diatur oleh suatu adat di mana aktivitas ekonomi tersebut le-bit bersifat pertukaran (Leur, 1967). Pada umum-nya pertukaran tersebut hanya dapat dilang-sungkan secara terbatas dengan kalangan pe-nguasa lokal, melalui aktivitas persembahan anu-gerah. JN Miksic menyebut sistem prosedur ini dengan istilan sistem emperion.

Berlangsungnya sistem emperion pada jaman Indonesia kuna tersirat pula pada catatancatatan pelaut-pelaut Cina yang melakukan misi politik dan niaga ke Nusantara. Barang dan bahan bernilai tinggi dan khas dari masing-masing daerah asal pelaku pertukaran mendominasi aktivitas tersebut (Groeneveldt, 1960). Nilai komoditas dari Nusantara yang dipertukarkan, menurut istilah Bambang Sumadio (1984), ... haruslah berupa barang bernilai tinggi untuk konsumsi kalangan atas

Lebih lanjut, menurut J.N. Miksic (1981) sistem ini didasari oleh kebutuhan penguasapenguasa lokal untuk mengumpulkan kekayaan. khususnya barang dan bahan langka, untuk motifmotif politik. Selain memiliki fungsi sebagai lambang status, bahan dan barang berharga tersebut diredistribusikan kepada komunitasnya sebagai anugerah yang dilandasi oleh "semangat kemurahhatian". Warga komunitasnya menerima anugerah tersebut meialui berbagai aktivitas, baik yang berwujud upacara maupun yang berbentuk dukungan material pada berbagai proyek umum

Kiranya bukanlah hal yang kebetulan bahwa anugerah berupa bahan dan barang dari penguasa Nusantara kuna sudah terekam pada sumber 
tekstual yang paling awal (abad ke-5 M), yaitu tugu yupa dari Kutai. Prasasti-prasasti tersebut menyuratkan sebagai berikut (Sumadio, 1984):

Sang Mulawarmman, raja yang berperada. ban baik, kuat dan kuasa. Sang Mulawarmman lelah mengadakan kendun (selamatan vang dinamakanl emas-amat-banvak buat peringatan kendun (selamatan) itulah tuqu batu ini didinkan oleh para berahmana (garis bawah oleh penulis).

Dengarkanlah oleh sekalian, Brahmana yang terkemuka, dan sekalian orang baik lainlainnya, tentang kebaikan budi Sang Mulawarmman, raja besar yang sangat mulia. Kebaikan budi ini ialah berwuind sedekah banvak sekali seolaholah sedekah kehidupan atau semata-mata pohon Kalpa (vang memberi segala keinginanl dengan sedekah tanah (xano dihadiahkan)... (garis bawah oleh penulis)

Tugu ini ditulis buat (peringatan) dua (perkara) yang telah disedekahkan oleh Sang Raja Mulawarnman, yakni sequnung minxak (kentall. denoan lamou serta malai bunga (madu? = pen.) (garis bawah oleh penulis).

Sang Mulawamman, raja yang mulia dan terkemuka, telah membeci sedekah 20.000 ekor sapi kepada para Brahmana yang seperti api... (garis bawah oleh penulis).

Dari masa yang sedikit lebih muda, informasi serupa disuratkan pula pada prasasti Tugu yang didapatkan di Tugu, Jakarta. Prasasti tersebut menyuratkan sebagai berikut (Sumadio, 1984)

Dulu sungai (vang bernamal = Candrabhaga celah digali oleh maharaia vang mulia dan memounvai lengan kencang dan kual bvakni raja Purnawarmanl bual mengalirkannua ke laut setelah (sungai ini) sampai di istana kerajaan yang termashur. Di dalam tahun keduapuluh-duanya dari takhta yang mulia raja Pumawarman yang berkilaukilauan karena kepandaian dan kebijaksanaannya serta menjadi panji segala raja, (maka sekarang) beliau menitahkan pula menggali sungai kang Rermai dan berair iernih Gemati namanza, setelah sungai itu mengalir di tengah tanah kediaman yang mulia Sang Pendeta neneknda (Sang Pumawarman). Pekenjaan ini dimulai pada hari yang baik, tanggal 8 paro-petang bulan Phalguna dan disudahi pada hari tanggal 13 paro-terang bulan Caitra, jadi hanya 21 saja, sedang galian itu panjangnya 6.122 tumbak. Selamatan baginva dilakukan deh oara brahmana disertai 1.000 ekor saoi yang dihadiahkan (garis bawah oleh penulis).

Prasasti-prasasti di atas, terutama pada bagian yang bergaris bawah, menggambarkan anugerah bahan dan barang bemilai tinggi dari penguasa kepada subordinatnya di dalam suatu kegiatan pesta jasa (kenduri atau selamatan). Bahkan pada prasasti Tugu disebutkan pula anugerah proyek pembangunan fisik berupa penggalian kanal atau terusan yang kemungkinan besar berhubungan dengan penanggulangan bencana banjir. Satu hal yang unik bahwa pesta jasa tersebut ditindaklanjuti oleh pendirian yupa atau tugu batu peringatan yang sekaligus berfungsi sebagai prasasti.

Gejala penyaluran bahan dan barang dalam pesta jasa pada Nusantara kuna juga dijumpai pada berbagai upacara penetapan sima. Dari rincian upacara penetapan sima yang direkam dalam beberapa prasasti abad ke-9/10 Masehi (Haryono, 1980) tersebut, terdapat dua elemen yang berkaitan dengan telaah ini. Pertama, adalah selalu (?) dijumpainya pemberian anugerah pasak-pasak oleh penguasa kepada pejabat pemerintah mau-pun kepada warga masyarakat. Kedua, hampir selalu dijumpainya informasi mengenai kegiatan makan bersama (kenduri?)

Sementara itu yang berkaitan dengan dukungan pada berbagai proyek fisik untuk kepentingan masyarakat, data prasasti dan naskah memberikan informasi yang cukup memadai. Dalam kajian Van Setten van der Meer, prasasti-prasasti dari fase Sindok dan Airlangga banyak menyuratkan tentang dukungan kedua penguasa tersebut kepada pembangunan dan perawatan sarana irigasi pengairan sawah rakyat. Sarana-sarana irigasi yang dibangun sekitar abad ke-10 tersebut berfungsi baik sampai dengan fase Majapahit, bahkan dikembangkan dalam intensitas yang semakin tinggi oleh penguasapenguasa abad ke-14/15 M. tersebut (Meer, 1979).

Untuk kepentingan kehidupan keagamaan masyarakat, penguasa Nusantara kuna memberikan dukungannya pada pembinaan sarana-sarana ibadah. Dalam Nagarakrtagama pupuh 82 bait ke-2 dan, 3 diperoleh gambaran tentang perhatian dan prakarsa penguasa kepada pembangunan dan pemeliharaan bangunan-bangunan keagamaan, biara, maupun perdikan yang berfungsi bagi kepentingan agama.

Selain kewajiban memberi kewajiban "membayar kembali" merupakan esensi di dalam potlatch (Mauss, 1992). Pada masyarakat Nusantara kuna, kewajiban tersebut tercermin pada pranata pajak, tenaga (gawaibuat haji), dan upeti (Kusumohartono, 1985). Menurut Boechari (1981), pajak adalah sumber pemasukan kas yang terpenting bagi kerajaan-kerajaan kuna di Nusantara. Pentingnya pajak bagi penguasa tercermin dalam uraian Nagarakrtagama pupuh 88 bait ke-6.

Sistem pajak pada masa itu dilembagakan dalam bentuk pajak tanah/hasil bumi, pajak perdagangan, dan pajak atas hasil kerajinan. Sementara itu pembayaran pajak -dan juga tenaga rakyat-- diterima oleh penguasa secara in natura maupun dalam bentuk alat tukar yang berlaku (Wuryantoro 1982) 
Penerimaan berupa upeti diterima oleh penguasa baik dari subordinatnya maupun dari pertukaran yang dilakukannya dengan misi dan pedagang asing (Nagarakrtagama pupuh 85 bait ke-5). Upeti dari luar tersebut merupakan sarana penumpukan komoditas bersifat asing dan langka di tangan penguasa yang diperoleh melalui pertukaran dengan komoditas khas produk hinterland. Pada gilirannya komoditas tersebut didistribusikan lagi kepada subordinatnya sebagai pencerminan dari kemurahhatiannya (Kusumohartono, 1985).

Rekonstruksi ini bukan model yang satusatunya terdapat pada masyarakat Nusantara Kuna. Di luar mekanisme pertukaran redistribusi, kemungkinan masih terdapat model-model lain yang berkembang. Tetapi fokus kajian ini akan ditekankan pada yang pertama.

\section{Pengujian Arkeologi Dan Permasalahannya}

Berkembangnya mekanisme pertukaran redistribusi pada masyarakat Nusantara kuna sudah terverifikasi melalui kajian sumber-sumber tekstual. Permasalahannya adalah sejauhmana kajian arkeologis berprospek diterapkan untuk menguji fenomena sejarah tersebut.

Dalam pengujian semacam itu, Hodder (1978) berpendapat bahwa unit-unit analisis yang patut mendapatkan perhatian utama adalah:

1. Pola permukiman pada jenjang makro; serta

2. Pola distribusi dari obyek yang dipertukarkan.

\section{Pola Permukimann}

Yang dimaksudkan di sini adalah distribusi dari permukiman yang digunakan oleh masyarakat yang saling berinteraksi pada kerangka temporal tertentu. Mengingat mekanisme pertukaran distribusi tersebut berlangsung di dalam masyarakat yang relatif terpusat dan hirarkis (centralised hierarchical societies) maka tidak cukup bagi kita hanya membatasi perhatian pada distribusinya saja namun juga hirarki permukimannya. Artinya, secara teoritik terdapat permukiman pada jenjang atas (pusat), serta permukiman pada satu atau lebih jenjang di bawahnya (Hodder dan Orton, 1976).

Dengan demikian maka pola permukiman tersebut tidak cukup hanya merupakan sebaran titik-titik, yang menandai situs-situs permukiman, pada suatu peta. Namun harus pula dapat ditunjukkan dengan akurat jenjang dari masing-masing permukiman pada jamannya. Di lapangan, jenjang dari situs permukiman diindikasikan oleh variabel ukuran (size) pemukimannya atau, mengingat semakin tinggi jenjangnya maka semakin luas juga situsnya (Paynter, 1983).

Selain pengujian melalui analisis pada pola (jenjang) permukiman, pengujian arkeologis atas fenomena pertukaran redistribusi dilakukan pula meialui analisis pada keberadaan dan jenjang pergudangan. Kerangka pikir di balik analisis pergudangan didasarkan atas kecenderungan penumpukan barang pada tangan penguasa sehingga dibutuhkan fasilitas penyimpanan pada setiap jenjang kekuasaan. Dengan demikian secara hipotetik akan didapati fasilitas pergudangan di permukiman pada jenjang atas, di mana gudang yang dimiliki oleh raja akan lebih besar ukurannya dari pada gudang milik elite lainnya.

Penelitian pola permukiman di Indonesia yang menghasilkan gambaran tentang sistem jen-jang pemukiman di masa lampau sejauh ini belum berhasil dicapai. Jaman kuna dengan informasi kesejarahan yang relatif lengkap, misalnya tentang Majapahit pun, baru dapat diperoleh informasi tentang toponim-toponim pentingnya saja, yang pada umumnya tersebar di kawasan timur Jawa (Eriawati J.,1991). Upaya untuk melakukan penjenjangan atas pemukiman-pemukiman jaman Majapahit belum tuntas dilakukan, kecuali atas sampel yang terbatas: Trowulan, Biting, Medowo, Caruban, dan Wonoboyo (Kusumohartono, 1993)

\section{Pola Distribusi Dari Obyek Yang Dipertukarkan}

Melihat informasi yang dapat dipetik dari sumber tektual di atas, maka diperoleh gambaran bahwa jenis obyek yang dipertukarkan sangat luas sifatnya. Beberapa contoh dari obyek yang dipertukarkan ialah: kain, perhiasan emas dan perak, makan dan minum, madu, minyak, hewan, tanah-lahan, lampu, biaya proyek, hasil bumi, kerajinan, alat tukar, tenaga, dan lain sebagainya. Tentu saja lingkup obyek yang yang dipertukarkan dan relevan bagi kajian arkeologi dibatasi hanya pada yang bersifat artefak (barang dan bahan). Itu pun yang tersisa sebagai artefak arkeologis tidak banyak. misalnya: perhiasan emas dan perak, lampu, kerajinan dari bahan yang tidak mudah rusak, mata uang, serta yang sejenis.

Atas artefak yang dipertukarkan, terdapat tiga variabel yang harus ditelaah:

1. Karakter kimiawi, petrografi, gaya dari artefak yang dikaji sebagai sarana penentu sumber atau asal dari artefak-artefak tersebut,

2. Menyusun model deskriptif tentang pola keruangan dari artefak yang diidentifikasikan sebagai komoditas pertukaran,

3. Ketiga atau terakhir, menyusun model rekonstruksi tentang organisasi masyarakat pelakunya dengan diperkaya oleh analogi dan komparasi pada model-model yang masih hidup maupun yang saat ini telah punah (Earle dan Ericson, 1977; Kusumohartono, 1993).

Secara umum terdapat tiga pendekatan deskriptif dalam penentuan pola keruangan tersebut. yaitu : 
1. Penyebaran titik dalam kawasan (regional point scatters),

2. Analisis regresi, dan

3. Analisis kecenderungan formasi antefak di permukaan (trend survace analysis) (Hodder dan Orton 1976).

Tentu saja pilihan atas masing-masing model analisis tersebut disesuaikan dengan masalah yang ingin dijawab serta serta visualisasi macam apa yang dituntut oleh penelitian yang bersang-kutan.

Dalam kenyataannya, tidak sepenuhnya mudah membedakan artefak yang dipertukarkan melalui mekanisme resiprokal atau pasar tradisional dengan artefak hasil pertukaran redistribusi. Dalam hal ini perhatian harus diberikan pada artefak-artefak dari jenjang-jenjang permukiman yang berbeda, sehingga dapat dipahami status artefaknya.

Dalam kaitan itu banyak faktor lain yang pa. tut pula diperhatikan guna memahami mengapa suatu artefak (dapat) dipindahtempatkan dari satu situs ke situs lain. Faktor lain tersebut, misalnya, adalah pentingnya efek jarak antar situs permukiman yang mau tidak mau berakibat bagi jelajah barang dan jasa. Beberapa faktor pembatas lain yang diajukan oleh Hodder (1978) adalah: perbedaan geografi, bahasa, politik, dan etnik. Sedang beberapa faktor pendorong adalah sebagai berikut : migrasi, perang, musiman, dan prestise.

Kajian arkeologi semacam itu tentu akan sangat mengandalkan pada unit analisis artefak tertentu (misalnya perhiasan emas, perak, mata uang, prasasti?) yang dijumpai pada situs-situs permukiman yang telah diketahui jenjangnya. Jelas hal itu merupakan penelitian yang berskala besar apabila semuanya dilakukan dalam bentuk penelitian primer.

\section{Penutup}

Ada dua gejala budaya -- migrasi dan pertukaran -- yang kemungkinan besar sulit dibedakan apabila kita hanya terpaku pada "data artefak pertukaran" semata. Sebenarnya hal ini dapat dengan jelas dibedakan mengingat pada dasarnya gejala pertukaran cenderung akan memperlihatkan persamaan pada artefak yang dipertukarkan saja. Sebaliknya gejala migrasi cenderung memperlihatkan persamaan pada seluruh sistem artefaknya.

Perbedaan ini dapat diidentifikasi apabila penelitian arkeologi dengan fokus pada artefak tertentu dilakukan pada skala ruang kawasan (regional). Tentu saja pola (jenjang) pemukiman di dalam kawasan yang spesifik tersebut harus sudah dapat digambarkan sebelumnya.

Nampaknya sudah dirasa perlu untuk mulai mengembangkan studi kawasan dalam arkeologi dengan prioritas pada penyusunan peta distribusional situs-situs semasa. Peta-peta semacam itu akan sangat bermanfaat sebagai dasar bagi studi penjenjangan permukiman melalui prinsip rank-size rule. Apabila peta pola permukiman semacam itu sudah dapat diperoleh maka pengujian arkeolo-gis atas mekanisme pertukaran redistribusional akan dapat dilakukan.

Permasalahan dari pengujian arkeologis terhadap berkembangnya mekanisme pertukaran redistribusi di antaranya adalah pada unit analisisnya yang relatif terbatas, baik jenis maupun distri-businya. Penelitian yang harus dilakukan pun harus berskala luas, pada jenjang-jenjang permukiman yang berbeda dalam kerangka temporal tertentu, dan menuntut dukungan sumberdaya yang relatif besar.

Penyelenggaraan penelitian semacam itu secara lebih efisien bisa dilakukan sepanjang akses ke berbagai sumber informasi penelitian arkeologi dapat dilakukan dengan mudah. Hal ini penting diperhatikan, mengingat sumber-sumber informasi tentang penelitian berbagai situs di Indonesia tersebar di berbagai lembaga. Jalan keluar yang terbaik adalah tersedianya satu sistem pangkalan data (data base) arkeologi terpadu yang meningkatkan aksesibilitas sumber-sumber informasi arkeologi tersebut.

\section{KEPUSTAKAAN}

Beilwood, Peter. 1987. The Polynesians, Prehistory of an Island People. Edisi revisi. London : Thames and Hudson Ltd.

Boechari. 1981. Ulah Para Pemungut Pajak di Dalam Masyarakat Jawa Kuna", dalam Majalah Arkeologi (IV/1-2). Lembaga Arkeologi FSUI.

Earle, Timothy K. 1982. Prehistoric Economics and the Archaeology of Exchange. New York : Academic Press.

Earle, Timothy $K$ dan Jonathan Ericson. 1977. Exchange Systems in Archaeological Perspective New York : Academic Press.

Eriawatti J., Yusmaini. 1991. Situs-situs Potensial Masa Majapahit, Kajian Toponim berdasarkan Perbandingan Data Tekstual dan Peta. Makalah dalam Rapat Analisis Sumber Tertulis Masa Klasik. Trowulan, 18-23 November 1991. 
Groeneveldt, W.P. 1960. Historical Notes on Indonesian and Malaya Compiled from

Chinese Sources Djakarta:Bhratara K.A.

Haryono, Timbul. 1980.Gambaran tentang Upacara Penetapan Sima, Arkeologi, Th. III No. 1-2. Lembaga Arkeologi FS UI.

Hodder, Ian \& Clive Orton. 1976. Spatial Analysis in Archaeology. Cambridge: Cambridge University Press.

Hodder, Ian. 1978. Social Organisation and Human Interaction: The Development of Some Tentative Hypotheses in terms of Material Culture, dalam I. Hodder (ed.) The Spatial Organisation of Culture. University of Pittsburgh Press.

Hodder,lan. 1982. Toward a Contextual Approach to Prehistoric Exchange. Cambridge: Cambridge University Press.

Jennings, Jesse D. (ed.). 1979. The Prehistory of Polynesia. England: Harvard University Press.

Kusumohartono, B. M. (1985). Strategi Adaptasi Lingkungan, Pola Ekonomi, Dan Pelestarian Kekuasaan, Paparan Mengenai Beberapa Data Jaman Indonesia Kuna. Berkala Arkeologi, 6(2), 3347. https://doi.org/10.30883/jba.v6i2.442

1991,Konsepsi 'Big Men' dalam Kehidupan Sosial - politik Indonesia Kuna, Makalah dalam Rapat Analisis Sumber Tertulis Masa Klasik. Trowulan, 18-23 November 1991.

1993 Artefak Logam Bagi Studi Pertukaran, dalam Proceedings AHPA IV 1991: Metalurgi Dalam Arkeologi. Jakarta: Departemen Pendidikan \& Kebudayaan.

Kusumohartono, B. (1993). Situs Wonoboyo: Pemukiman Kuna Pada Jenjang Mana?. Berkala Arkeologi, 13(3), 47-58. https://doi.org/10.30883/ jba.v13i3.616

Leur, J.C. van. 1967. Indonesian Trade and Society. The Hague: W. van Hoeve.

Malinowski, B. 1922. Argonauts of the Western Pacific. London: Routledge and Keegan Paul
Mauss, Marcel. 1992. Pemberian, Bentuk dan Fungsi Pertukaran di Masyarakat Kuno (terjemahan Parsudi Suparlan). Yayasan Obor Indonesia.

Meer,N.C. van Setten van der. 1979. Sawah Cultivation in Ancient Java. Canberra ANU Press. Miksıc, John N. 1981 Perkembangan Teknologi, Pola Ekonomi dan Penafsiran Data Arkeologi di Indonesia, Arkeologi, Th. IV No. 1-2. Lembaga Arkeologi FS UI

Oliver, Douglas, 1955. A Solomon Island Society; Kinship and Leadership among the Siuai of Bougainville. Cambridge, Mass.: Harvard University.

Paynter, Robert W. 1983. Expanding the Scope of Settlement Analysis, dalam J.A Moore dan A.S. Keene (peny.) Archaeological Hammers and Theories. New York Academic Press.

Rappaport, Roy A. 1984. Pigs for the Ancestors, Ritual in the Ecology of a New Guinea People. New Haven and London: Yale University Press

Schiffer,Michael,B.,1976. Behavioral Archaeology. New York: Academic Press.

Soejono, R.P. (peny.). 1984. Sejarah Nasional Indonesia, I. PN Balai Pustaka.

Sumadio, Bambang. 1984. Sejarah Nasional Indonesia, II. PN Balai Pustaka

Wuryantoro,Edhie., 1982. Pajak dalam Abad Kesebelas dan Keduabelas, dalam MISI (XI/O1). FSUI 